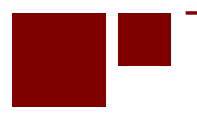

C E N T E R for RETIREMENT RESEARCH at BOSTON COLLEGE

\title{
CALCULATING NEUTRAL INCREASES IN RETIREMENT AGE BY SOCIOECONOMIC STATUS
}

Geoffrey T. Sanzenbacher, Anthony Webb, Candace M. Cosgrove, and Natalia S. Orlova

CRR WP 2015-22

August 2015

Center for Retirement Research at Boston College

Hovey House

140 Commonwealth Avenue

Chestnut Hill, MA 02467

Tel: 617-552-1762 Fax: 617-552-0191

http://crr.bc.edu

Geoffrey T. Sanzenbacher is a research economist at the Center for Retirement Research at Boston College (CRR). Anthony Webb is a senior research economist at the CRR. Candace M. Cosgrove is a mathematical statistician at the U.S. Census Bureau. Natalia S. Orlova is a research associate at the CRR. The research reported herein was pursuant to a grant from the Alfred P. Sloan Foundation. The findings and conclusions expressed are solely those of the authors and do not represent the views of the Alfred P. Sloan Foundation, the U.S. Census Bureau, or Boston College.

This paper is released to inform interested parties of research and to encourage discussion. Any views expressed on statistical, methodological, technical, or operational issues are those of the authors and not necessarily those of the U.S. Census Bureau.

(C) 2015, Geoffrey T. Sanzenbacher, Anthony Webb, Candace M. Cosgrove, and Natalia S.

Orlova. All rights reserved. Short sections of text, not to exceed two paragraphs, may be quoted without explicit permission, provided that full credit, including $(\subset)$ notice, is given to the source. 


\begin{abstract}
About the Center for Retirement Research
The Center for Retirement Research at Boston College, part of a consortium that includes parallel centers at the University of Michigan and the National Bureau of Economic Research, was established in 1998 through a grant from the Social Security Administration. The Center's mission is to produce first-class research and forge a strong link between the academic community and decision-makers in the public and private sectors around an issue of critical importance to the nation's future. To achieve this mission, the Center sponsors a wide variety of research projects, transmits new findings to a broad audience, trains new scholars, and broadens access to valuable data sources.
\end{abstract}

Center for Retirement Research at Boston College

Hovey House

140 Commonwealth Ave

Chestnut Hill, MA 02467

Tel: 617-552-1762 Fax: 617-552-0191

http://crr.bc.edu

Affiliated Institutions:

The Brookings Institution

Massachusetts Institute of Technology

Syracuse University

Urban Institute 


\begin{abstract}
As the gap between retirement resources and needs grows, many researchers have prescribed the antidote of working longer. But this prescription may disadvantage lower socioeconomic status (SES) households because they have shorter lives than higher-SES households, and working longer may increase existing disparities in retirement durations. This paper uses data from the National Longitudinal Mortality Study to quantity these disparities by SES since 1979, using education as a proxy for SES. The paper finds that age-65 life expectancies have increased for all levels of educational attainment but that the gains have been much greater for those in the top quartile. The paper uses these calculations to determine hypothetical retirement ages that hold constant for each SES group the 1979 ratios of time spent in retirement to time spent working. The findings suggest that all educational groups can work longer today than in the past, while spending a similar fraction of their lives in retirement; those in the top quartile of educational attainment can work a full one to two years longer than those in the bottom quartile and still maintain their 1979 ratios.
\end{abstract}




\section{Introduction}

As the gap between retirement needs and resources grows, many researchers have prescribed the antidote of working longer. For individuals in good health, working longer increases monthly Social Security benefits, allows them to accumulate more savings, and reduces the number of years that savings need to cover. To some extent, individuals seem to be taking the prescription to heart - the average retirement age has increased over the last few decades. ${ }^{1}$ And since life expectancies are also increasing, it seems reasonable that people might choose retirement ages that permit them to spend similar fractions of their lives in work versus retirement compared to workers from past generations.

While the need to work longer holds across all socioeconomic strata, longevity gains may be unequally distributed. Low socioeconomic status (SES) workers may have experienced smaller increases in longevity in recent decades. If mortality disparities between high- and lowSES individuals are increasing, policy proposals that encourage delayed retirement, such as an increase in Social Security’s Early Eligibility Age (EEA) or Full Retirement Age (FRA), may increasingly disadvantage low-SES individuals, causing them to spend higher fractions of their lives at work compared to their higher-SES counterparts. Indeed, several studies have expressed concern about the impact of requiring individuals with shorter life expectancies to work longer. ${ }^{2}$ Understanding how mortality disparities have changed over time is therefore a crucial contribution to any discussion of the equity of these policies. Yet, until very recently, little research has focused on trends in mortality by SES.

To address this gap in the literature, this paper uses National Longitudinal Mortality Study (NLMS) data to calculate the extent to which mortality disparities increased between 1979 and 2011, using education as a proxy for SES. ${ }^{3}$ However, using actual educational attainment as a proxy for SES may overstate differences in longevity gains by SES because high school dropouts have become a much smaller group over time. Prior to World War II, fewer than half of individuals graduated from high school; today over 80 percent do. The expanding mortality gap between high school dropouts and the more educated may simply reflect the increasing selectivity of the dropout group, not any underlying change in the relationship between SES and

\footnotetext{
${ }^{1}$ Munnell (2015).

${ }^{2}$ See, for example, Aaron and Burtless (2013), Panis et al. (2002), Leonesio, Vaughn, and Wixon (2003), Weller (2005), Haverstick et al. (2007), Turner (2007), Munnell and Libby (2007), Cutler (2009), Monk, Turner, and Zhivan (2010), and Cutler et al. (2011).

${ }^{3}$ The National Longitudinal Mortality Study began yearly collection in 1979.
} 
mortality. To control for this possibility, we assign equal shares of individuals in each birth cohort to quartiles of educational attainment.

To inform discussions of the equity of increasing the retirement age, the paper calculates counter-factual retirement ages that vary by educational quartile and gender and hold constant the fraction of life spent in work and retirement for each SES group between 1979 and 2011. Although the primary interest of this paper is the life expectancy of workers reaching retirement age, it is worth noting that pushing the retirement age back also means more individuals will die before reaching that age (and thus experience only years in work). Therefore, these counterfactual retirement ages are calculated in two ways: 1) for workers conditional on surviving to the 1979 FRA of 65 and 2) for workers conditional on reaching age 22 (allowing some individuals to die prior to reaching retirement). These calculations illustrate the extent to which policies that encourage delayed retirement and treat low- and high-SES workers alike may increase disparities in retirement duration relative to working life. To date, such calculations have been hampered by the absence of estimates of mortality trends across SES groups.

We find that both age-65 and age-22 life expectancies have increased for all SES groups. If morbidity tracks mortality, all groups should be able to work longer in the future. At the same time, we also find that differences in life expectancies between those in the bottom educational quartile and those in the top have widened over time. For example, between 1979 and 2011, life expectancy at age 65 for males in the lowest to highest educational attainment quartiles increased by 4.0, 5.1, 5.5 and 6.1 years, respectively. The trends are similar for women, albeit with smaller improvements, at 1.4, 2.7, 2.3 and 3.2 years, respectively. ${ }^{4}$ These patterns mean that the length of time spent in retirement has increased disproportionately for the most educated. To illustrate this point, a male in the bottom educational quartile who started work at 22 and survived to retire at the Full Retirement Age of 65 in 1979 would be expected to spend 0.36 years in retirement for each year spent working. Due to their longer age-65 life expectancy, the comparable number for an individual in the top quartile in 1979 is 0.44. In 2011, the individual in the bottom quartile could retire at age 68.1 and achieve his historical ratio of years working to retirement of 0.36 , while an individual in the top quartile could retire at $69.6-1.5$ years later - to maintain his ratio

\footnotetext{
${ }^{4}$ Calculations reported here are so-called "period" calculations and assume that individuals reaching 65 in 2011 have 2011 mortality as a 66 year old, 2011 mortality as a 67 year old, and so on. Calculations using the alternative “cohort” approach, whereby individuals reaching age 65 in 2011 are assumed to have 2012 mortality at 66, 2013 mortality at 67 , and so on are not shown in this paper for reasons discussed below.
} 
of 0.41 . While both sets of workers can work longer than they could in 1979, individuals in the top quartile can retire much later while enjoying the same relative time spent in retirement as their 1979 counterparts.

The remainder of this paper is organized as follows: the first section summarizes the literature; the second section describes the data; the third section describes the empirical analysis; the fourth section the results; and the final section concludes.

\section{Literature}

While little attention has been given to mortality trends by SES, a large body of research has established a cross-sectional relationship between mortality and SES. One cross-sectional study - using NLMS data for 1979-1989 - found that high-SES individuals have substantially lower mortality rates (Brown, Liebman, and Pollet 2002), but this study did not explore trends in SES mortality differentials over time. A more recent study found an inverse correlation between lifetime earnings and mortality that extends up through most of the income distribution, but had limited data available to study trends (Waldron 2013).

Most studies of mortality trends, for example Lee and Carter (1992), do not decompose trends by SES, and the few studies that do show mixed results. Rogot, Sorlie, and Johnson (1992) found that education-related mortality differentials were the same in 1985 as those found by Kitagawa and Hauser (1973) in 1960. In contrast, Pappas et al. (1993) reported widening SES mortality differentials between 1960 and 1986. More recently, Waldron (2007) used labor market earnings as a proxy for SES and found that mortality has declined more rapidly among individuals in the top half than among those in the bottom half of the earnings distribution. One problem with using earnings to define SES is that earnings, unlike education, are affected by health shocks. Using earnings as a proxy for SES may exaggerate SES mortality differentials if health shocks both reduce earnings and increase mortality.

Olshansky et al. (2012) do use education and claim a startling three-year reduction in age-20 life expectancy among white males with less than a high school education from 1990 to 2008, with no corresponding reductions among blacks and Hispanics. But their estimates do not account for the changing educational distribution over that time period. Furthermore, their estimates are sensitive to misestimation, because separate datasets are used in the numerator and 
denominator of the mortality rate. ${ }^{5}$ Bound, Geronimus, and Rodriguez (2014) refine the estimates of Olshansky et al. using the same separate datasets but use educational rank instead of absolute level (i.e., the bottom quartile by grade completed is used instead of less than high school, with procedures for breaking "ties" used as needed for those with the same grade completed) and find that this adjustment eliminates the finding that less-educated males experienced a reduction in age-20 life expectancy from 1990 to 2008. This finding highlights the potential importance of the educational adjustment described later.

\section{Data and Sample}

Unlike some prior research, this study uses a single dataset, the National Longitudinal Mortality Study (NLMS), to estimate trends in mortality by SES. The advantage of the NLMS is that it includes both SES measures and the date of death. The paper uses quartiles of educational attainment as a proxy for SES, avoiding the difficulties associated with using earnings.

The NLMS consists of individual-level data from the CPS and from the 1980 Census cohort - which provide data on SES - matched to data from death certificates obtained from the National Center for Health Statistics. The NLMS includes 33 samples from the Annual Social and Economic Supplements to the CPS; one sample from March 1973 and one collected each year from March 1979 to March 2011. The NLMS also includes five samples taken from the basic monthly CPS data for February 1978, April 1980, August 1980, December 1980, and September 1985, and from one 1980 Census cohort. ${ }^{6}$ These 39 samples include SES data on 3.8 million individuals of which just 200,000 (5 percent) are excluded from the NLMS because they lack sufficient information to match them to death certificates. Of the remaining 3.6 million observations included in the NLMS, there were over 500,000 cases of recorded mortality in the 2011 data, the last year that the CPS samples were matched to death certificates.

Due to its structure, the NLMS contains two groups of variables collected at different points in time. For each individual, demographic and socioeconomic characteristics, such as age, education, gender, income, earnings, and employment status, are obtained at the time of their CPS or Census interview, marking the beginning of their appearance in the NLMS. For

\footnotetext{
${ }^{5}$ Wang et al. (2013) report a widening in disparities in county-level mortality disparities from 1985 to 2010 . But this result might reflect an increase in geographic segregation by SES.

${ }^{6}$ Information on year of birth and CPS sample year are not available in the public-use version of the NLMS. Because these variables are critical to the analysis presented here, all analyses were conducted on restricted-access data through employees at the U.S. Census Bureau.
} 
individuals who die between their sample year and 2011, additional information on date, cause, and location of death that is collected from death certificates is included.

Our initial sample consists of all NLMS cohorts beginning in 1979 or later except for the 1980 Census cohort, which excludes information on education. The initial sample consists of individuals born between 1877 and 1959 and ages 25 or older at their sample year, for a total of 1.7 million observations. After assigning individuals to educational quartiles, the final sample used to conduct the analysis is slightly smaller - 1.5 million people - since it excludes individuals missing data for variables used directly in this reassignment: ethnicity, gender, industry (if working), occupation (if working), family income, family size, residence in a Metropolitan Statistical Area (MSA), and state. ${ }^{7}$ More detail on how these variables are used in the educational reassignment algorithm is provided in the empirical analysis section.

\section{Empirical Analysis}

Like this study, Brown, Liebman, and Pollet (2002) use NLMS data. But in contrast to their use of actual education instead of quartiles and the restriction that the relative mortality rates of SES groups remain constant over time, we allow relative mortality rates to vary over time by gender, age, and educational quartile. The empirical analysis has several steps. First, the NLMS data are benchmarked against a common source of mortality data - U.S. Social Security Administration (SSA) period mortality tables - to ensure consistency. The second step is to assign people to an educational quartile so as to maintain the distribution of education over time. The third step is to use the NLMS data to calculate annual mortality rates by year, education, and gender. These mortality rates serve as inputs into a mortality regression that identifies levels and changes over time in mortality rates by SES. The final step is to use the regression outputs to construct mortality tables that are then used to calculate retirement ages that retain the 1979 relationships between the durations of periods spent working and in retirement.

\section{Benchmarking the NLMS data}

To confirm consistency with other widely used mortality data, we first benchmark the NLMS mortality data against SSA cohort life tables. ${ }^{8}$ These tables show mortality rates by age

\footnotetext{
${ }^{7}$ See Table 1 for detail on how the sample is restricted from the full sample to the final sample used in estimation.

${ }^{8}$ The Social Security Administration (SSA) calculates mortality rates using different methods for different years of death. To calculate mortality rates for 1900-1967, the SSA divides the number of deaths for each age and gender from the National Center for Health Statistics by the mid-year Census estimate of the population for that age and
} 
and birth cohort. To conduct the comparison, NLMS data for individuals from the 1877-1959 birth cohorts are used to calculate mortality rates using the following formula:

$$
m_{x, t}=\frac{l_{x-1, t-1}-l_{x, t}}{l_{x-1, t}}
$$

where $m_{x, t}$ is the mortality rate and $l_{x, t}$ is the number of individuals alive at age $x$ born at time $t$. For example, $m_{75,1920}$ would be the mortality rate for a 75 -year-old born in $1920 .^{9}$

To compare the mortality rates calculated in equation (1) to those provided by the SSA, we calculate the unweighted average mortality rate at each age across the 1877-1959 birth cohorts in the NLMS data. ${ }^{10}$ We compare these averages with the corresponding values reported in SSA cohort life tables for the 1877-1959 birth cohorts. ${ }^{11}$ Figures $1 \mathrm{a}$ (men) and 1b (women) report results of this comparison. Figure 1a shows that the NLMS data for men closely match SSA life tables, with a small discrepancy above age 91, at which point the NLMS sample shows slightly lower mortality. At high ages, the NLMS samples become quite small so some discrepancies are not surprising. For women, Figure 1b shows the two series match closely at all ages. Figures $1 \mathrm{a}$ and $1 \mathrm{~b}$ confirm that the NLMS data are largely representative of the mortality experience of the relevant birth cohorts as estimated by the SSA.

\section{Reassigning Educational Attainment}

A major contention of this paper is that using an individual's level of educational attainment - high school, college, etc. - to measure SES may overstate changes in the mortality gap over time. This overstatement is possible because the share of high school dropouts has become much smaller over time and represents a more disadvantaged SES group than in the past. A widening mortality gap between dropouts and those with more education could either

gender. After 1968, the SSA uses this same method for all individuals under age 65, but uses Medicare data to calculate the mortality rate for individuals over age 65. Medicare data have the advantage of containing the number of deaths and the number of individuals alive for the population within the same dataset.

${ }^{9}$ In the NLMS, a small fraction of individuals included in the sample have not yet been matched to a death certificate, despite having obviously reached ages where they are deceased (e.g., 135 years old). If they are not accounted for, these so-called immortals result in mortality rates that are artificially low at high ages. To account for this data issue, we identify the number of individuals over 105 years old and alive in 2011 for each birth cohort and subtract these individuals from the denominator of equation (1) for years in which they were in the sample.

${ }^{10}$ Results were similar when weights representing the number of observations in the NLMS were used.

${ }^{11}$ We include only those age-year combinations for which we have observations and for which there are at least five observations in the NLMS. 
represent the actual impact of rising inequality by SES or simply the increasing disadvantage of this least-educated group.

To address this issue, we reassign educational attainments so that, for each birth cohort, an equal number of individuals is in each education quartile. We first estimate the following ordered probit model:

$$
y^{*}=x \beta+e
$$

where $y=0$ if $y^{*}$ (the exact but unobserved dependent variable) is $\leq \alpha_{1}$, the dividing line between less than high school and high school education; $y=1$ if $\alpha_{1}<y^{*} \leq \alpha_{2}$, the dividing line between high school and some college; $y=2$ if $\alpha_{2}<y^{*} \leq \alpha_{3}$, the dividing line between some college and college graduation; $y=3$ if $\alpha_{3}<y^{*}$, and $x$ is a vector of correlates of educational attainment including ethnicity, gender, industry, occupation, family income decile, family size, residence in an MSA, and state. In this specification, the ethnicity variable is defined as white non-Hispanic, black non-Hispanic, other non-Hispanic, and Hispanic; agriculture is grouped with manufacturing and construction, trades with personal services and entertainment; and occupation is defined as white or blue collar. Family income deciles are defined within birth cohorts and separately for households where the head of the household was retired versus working. ${ }^{12}$

We initially place those with less than a high school education in the bottom quartile, those with a high school education in the second quartile, those with some college in the third quartile, and college graduates in the top quartile. If more than 25 percent of individuals in a given birth cohort have a college degree, we reassign individuals from the top to the third quartile to reduce the size of the top quartile to 25 percent of the total. The probability of being selected and moved is proportional to the probability that someone with that individual's characteristics would not have graduated from college. Marginal college graduates are more likely to be reassigned. We then proceed in like fashion to reassign individuals with some college education to the second quartile, and those with a high school education to the bottom quartile, until we have equal numbers in each quartile. Among older birth cohorts, more than a quarter of individuals failed to graduate from high school, and the procedure for these cohorts starts with those with less than a high school education and works up through the quartiles.

\footnotetext{
${ }^{12}$ For couples, the head of household was assumed to be male.
} 


\section{Constructing Period Life Tables}

We then use the NLMS data to construct period mortality tables that vary with age, year, gender, and educational quartile. Even with this large sample, it is infeasible to allow mortality rates to vary flexibly with all of the above factors. Therefore, constraints are imposed.

Specifically, mortality is assumed to increase exponentially with age, a feature of mortality data that previous research dating back to Gompertz (1825) has shown to hold true until advanced ages. We further assume that, within each gender and SES group, all age groups experience the same annual percentage changes in their mortality rates.

These assumptions lead us to estimate the following model for each gender and educational quartile:

$$
\ln \left(m_{x, t}\right)=a+b(x-52)+c(t-1979)
$$

where $a$ is a mortality rate at age $52, b$ is the exponential rate at which mortality increases with age, and $c$ is the annual percentage rate of decline in mortality from 1979 onward.

\section{Results Using Educational Quartiles}

This section presents three types of results: 1 ) the regression results from the mortality models; 2) the corresponding increases in life expectancy by education; and 3) the changes in retirement ages between 1979 and 2011 that are consistent with neutral retirement-to-work ratios.

\section{Mortality Models}

Table 2 illustrates the results of estimating equation (1) separately for males and females and then overall, but without making distinctions for educational quartile. ${ }^{13}$ This "pooled" approach provides a useful benchmark of the NLMS data against other mortality data. The “Overall” result, which does not distinguish the sample by gender, indicates that between 1979 and 2011 the annual reduction in mortality averaged 1.1 percentage points per year. This rate of

\footnotetext{
${ }^{13}$ In these regressions, each age and gender cell is weighted by the share of deaths in the year that occurred for that cell. In other words, the regression attempts to fit mortality rates within a year placing the most weight on ages with the most deaths.
} 
decline is slightly higher than that estimated by Social Security for a similar time-period - 1.0 percent per year between 1982 and 2011. ${ }^{14}$ But the proximity of these overall estimates between the NLMS and SSA data mask larger discrepancies across genders. While the NLMS and SSA data suggest similar rates of decline for women -0.7 versus 0.6 percent per year respectively - the estimates are not as close for men. The NLMS data show men experienced annual declines in mortality averaging 2.0 percent between 1979 and 2011 while the result from SSA is a lower 1.3 percent for a similar time period (1982 to 2011). ${ }^{15}$ While other authors have detected mortality improvements around and even above 2 percent for men at certain ages and for some time periods, ${ }^{16}$ this finding causes us to proceed with caution. Specifically, we will approach all life expectancy calculations from a "period" approach which avoids projecting mortality improvements observed in the NLMS data between 1979 and 2011 into the future. This approach seems especially prudent since some developments which may have caused mortality rates to improve over the past 30 years will likely not continue into the future (e.g., smoking cessation), while other trends may offset mortality improvements (e.g., higher rates of obsesity).

Table 3 shows the regression results by gender and educational quartile. The first four rows of results are for men and the second four rows are for women. These coefficients can be used to estimate mortality per 100 of the population. For example, if we wished to use the NLMS data to predict mortality among 80 -year-old males in the bottom quartile in 1990, we would perform the following calculation:

$$
m_{x, t}=\exp (0.224+0.076(80-52)-0.015(1990-1979))
$$

yielding a predicted mortality rate .0885, or 8.85 per 100 .

In all the models, mortality rates increase with age and decrease over time as can be seen through the positive coefficients on the age variable and the negative coefficients on the years that have passed since 1979. The model can also be used to predict mortality rates at other ages. For example, the age-65 mortality rates in 1979 for males are - from the lowest to highest educational quartiles -3.35 , 3.02, 2.92, and 2.17 respectively.

\footnotetext{
${ }^{14}$ U.S. Social Security Administration, “Long-Range Demographic Assumptions for the 2015 Trustees Report.”

${ }^{15}$ U.S. Social Security Administration, "Long-Range Demographic Assumptions for the 2015 Trustees Report."

${ }^{16}$ For example, Lu and Wong (2011) report yearly motality improvements for males age 60 to 90 ranging from 1.5 to 2.5 percent using the Human Mortality Database from 1995-2006.
} 
The results can also be used to explore differences, based on education, in mortality reductions over time, as is shown in the second column of Table 4. Most importantly, the results indicate that men and women in the top quartile have enjoyed significantly faster declines in mortality from 1979 through 2011 than have those in lower quartiles. ${ }^{17}$ For males, annual reductions in mortality rates - ranging from the lowest to highest quartiles of educational attainment - are estimated at 1.5, 2.0, 2.2, and 2.5 percent, respectively (as shown in the second column of Table 3). The pattern is similar for women, with smaller annual reductions in all education quartiles than for men - 0.5, 1.0, 0.9 , and 1.2 percent, respectively.

Interestingly, as can be seen by positive coefficient differences in the first column of Table 4, comparing the coefficients on age among educational quartiles for both men and women shows that age-related increases in mortality are highest for those in the top quartile. This result implies that beyond some age, mortality is actually higher among those with more education. For example, comparing males in the second quartile with those in the top quartile, and using 1979 period mortality, we calculate that this crossover point occurs at age 87 in 1979, although no such cross-over occurs in 2011 until implausibly late ages. Our 1979 finding is consistent with Brown, Liebman, and Pollet (2002) who use data from the late 1970s and early 1980s to obtain a mortality crossover at age 87 when comparing white males with some college to those with less education. Other authors have reported mortality crossover at old ages along the dimension of race, including most recently Yao and Robert (2011) who find that blacks at high ages have lower mortality than whites. ${ }^{18}$

\section{Life Expectancy by Educational Quartile}

The estimates above can be used to estimate survivor probabilities by SES starting as early as age 25. As an illustration, Figure 2a compares cumulative survival probabilities for men in the first and fourth quartiles of educational attainment, starting at age 25 for individuals turning 65 in 1979 and in 2011 (the 1914 and 1946 birth cohorts). Figure 2b shows the same for

\footnotetext{
${ }^{17}$ In Table 4, the difference for males between the highest and third education quartiles is visible in the third row and is a statistically significant 0.3 percent. For females, the corresponding difference is 0.4 percent and is also statistically significant.

${ }^{18}$ Other examples include Johnson (2000) and Lynch, Brown, and Harmsen (2003). In general, two hypotheses are put forward to explain mortality of lower-SES individuals as compared to higher ones at old ages: 1) selective mortality, whereby high mortality at younger ages among low-SES individuals results in only those with low mortality making it to very old ages; or 2) more frequent misreporting of age by low-SES individuals (specifically younger individuals claiming to be older). In any case, the phenomenon is common in the literature.
} 
women. Cumulative survival probabilities vary with socioeconomic status and are higher in 2011 than in 1979. For both men and women, the cumulative survival probability increased from 1979 to 2011 for both groups and by much more for the fourth quartile.

Table 5 uses the estimates presented above to obtain life expectancies for those who survive to age 65 and seperately for age 22. These life expectancies serve as inputs to calculate fair increases in retirement ages. The results reported in Table 5 are so-called "period” estimates of life expectancy. These estimates assume that mortality rates become fixed when the individual hits age 65 or 22. For example, this assumptions means that individuals who reach 65 in 2011 do not continue to experience mortality improvements as they age - e.g., when 66 in 2012 they will have the same mortality as a 66-year old in 2011, when 67 in 2013 they will have the same mortality as a 67 year-old in 2011, and so on.

This approach is in contrast to a "cohort” based approach, which allows mortality to reflect age and birth year. For example, a person who is born in 1946 and reaches 65 in 2011 experiences 2011 mortality rates for a 65-year-old in 2011 and 2012 mortality rates for a 66year-old in 2012. In contrast, a 65-year-old born one year later, in 1947, reaches 2012 mortality rates for a 65-year old in 2012 and 2013 mortality rates for a 66-year old in 2013. While the cohort approach has the advantage of capturing the mortality rates of specific birth cohorts, it has the distinct disadvantage of projecting mortality rates into the future using a window of observation that may not represent longer-term trends. Because of this disadvantage, and because the NLMS data produce estimates for male mortality improvements between 1979 and 2011 that are on the high side of existing estimates, this paper focuses on the period approach. Because our estimates show the most educated experienced the largest declines in mortality between 1979 and 2011, this approach is conservative relative to the cohort approach which would project the widening inequality of the past 30 years into the future.

Using this approach, men who survive to age 65 in 1979 had life expectancies - ranging from the lowest to highest quartiles - of 77.5, 77.7, 77.8, and 78.9 years, respectively. By 2011, men experienced life expectancy increases of 4.0, 5.1, 5.5, and 6.1 years. Men who have only survived to age 22 have lower life expectancies, 68.8, 70.6, 71.0, and 74.3 respectively, but have seen bigger improvements between 1979 and 2011 at 6.1, 7.4, 7.9, and 7.9. Clearly, the highest gains are centered on the highest quartiles of the education distribution. The corresponding numbers for 65-year-old women in 1979 were 82.3, 82.6, 82.9, and 83.4 years, with increases by 
2011 of 1.4, 2.7, 2.3, and 3.2 years. For women at age 22, the corresponding numbers are 76.8, 78.5, 79.3, and 80.5 with improvements of 1.9, 3.5, 2.9, 3.9. For both men and women, the age65 life expectancy increased across all educational groups and increased most for those in the top quartile.

\section{Calculating Neutral Increases in Retirement Ages}

The overall progressivity of the Social Security program depends on several factors, including, importantly, the progressivity of the benefit formula. But this effect is partially offset by the relationship between SES and longevity. In this section, we use a simple measure of the SES-longevity relationship: the ratio of the expected number of years spent in retirement to the expected number of years spent working. Table 6 reports these ratios for individuals who begin work at 22, ${ }^{19}$ who experience 1979 period mortality at all ages, and retire at the Full Retirement Age of 65 and again for those experiencing 2011 mortality at all ages, using both the 1979 Full Retirement Age of 65 and the 2011 Full Retirement Age of 66.

Holding the Full Retirement Age constant at age 65, the mortality reductions that occurred between 1979 and 2011 increased the ratio of years spent in retirement to years spent working for all educational quartiles. For example, conditional on surviving to age 65, men in the bottom quartile who started working at 22 and worked 43 years before retiring at 65 saw an increase from 0.29 years of retirement for each year of work to 0.38 , and men in the top quartile saw an increase from 0.32 to 0.46 . But some men die before attaining age 65. Conditional on surviving only to age 22, the ratios are lower but the improvements similar: an increase from .23 to 0.33 for the bottom quartile and from 0.29 to 0.45 for the top quartile. Conditional on attaining age 65,, the bottom quartile of women experienced increases in the retirement-to-work ratio from 0.40 to 0.44 between 1979 and 2011 and those in the top quartile had an increase from 0.43 to 0.50 . Conditional only on attaining age 22, the ratios for women are again lower but improvements still exist: 0.36 to 0.40 for the bottom quartile and 0.39 to 0.45 for the top. Simply, all educational quartiles experienced an increase between 1979 and 2011, and it was greatest for the top quartile. In the third column, which incorporates the increases in the Full Retirement Age, the picture changes somewhat, but even females in the lowest education quartile

\footnotetext{
${ }^{19}$ In terms of measuring inequality, this assumption is somewhat conservative. In realtity, individuals with less education also start work much earlier than 22. However, for illustrative purposes it is easiest to assume all workers start their careers at the same point.
} 
- the group experiencing the smallest reductions in mortality - saw an increase in the ratio of years worked to years expected in retirement if retiring at 66 instead of 65 regardless of whether the calculation is started at age 22 or 65 .

Table 7 reports the Full Retirement Ages, by educational quartile, that would preserve the 1979 ratios between years spent in retirement and working. The first column reports the retirement ages that would hold the 1979 ratios constant by SES - so that 1979 inequalities would be maintained but not exacerbated - using 2011 period mortality. Under this assumption, men in the bottom quartile could work an additional 3.1 years once surviving until 65, retiring at 68.1, while those in the top quartile could retire at 69.6 - a full 1.5 years later than the bottom quartile. For women surviving to 65 , those in the bottom quartile need to retire at 66.0 to maintain the 1979 ratio, while those in the top quartile can work until 67.2 to maintain the 1979 status-quo. As Table 7 shows, the overall conclusion doesn't change when performing the calculations for age-22 survivors.

The second column reports retirement ages assuming that each educational group needs to retire at an age that will provide them with the average 1979 ratio of years in work to retirement - so that all workers enjoy the same ratio of years spent at work to years in retirement. Under this assumption, the differences in 2011 between top- and bottom-quartile retirement ages are more extreme. For men surving until 65 in 2011, those in the bottom quartile can work an additional 2.7 years and retire at 67.7 , spending 0.30 years in retirement for each year in work, the average 1979 ratio. Those in the top quartile can retire at 70.4, a full 3.3 years longer, while maintaining the 0.30 ratio. For women, the corresponding numbers are 65.6 and 67.6. The results are qualitatively similar if the calculation is instead started at age 22. The results in Table 7 highlight the two major findings of this paper: due to rising longevity, all workers today can work longer than in 1979 while maintaining their 1979 ratio of years spent in retirement to work, but the number of additional years differs substantially by SES.

\section{Conclusion}

To strengthen income security in retirement, many researchers have suggested that Americans work longer. One policy proposal that is consistent with encouraging longer worklives - as well as reducing Social Security's long-term financial shortfall - is increasing Social Security's Early Eligibility Age or Full Retirement Age. To the extent that such changes 
do lead to longer worklives, a potential concern is that they might disadvantage low-SES individuals who, on average, die younger, and would lose a larger proportion of their retirement years. On the one hand, assuming morbidity tracks mortality, individuals of all SES groups should be able to work longer than they did in 1979, because mortality has improved across the board.

On the other hand, the analysis also shows that disparities in life expectancy that existed in 1979 have grown over time. This finding implies that efforts to encourage individuals to work longer will mean that low-SES workers will spend a smaller fraction of their lives in retirement. This difference is non-trivial. For men to simply maintain the same disparity in years spent in retirement to years spent working that existed in 1979 - and assuming a 1979 retirement age of 65 - those in the top quartile can work a full 1.5 years longer than those in the bottom quartile. For women, the corresponding number is 1.2 years. Policy experts rightly contend that working longer would improve individuals' retirement finances, but this growing disparity should be considered. 


\section{References}

Aaron, Henry J. and Gary Burtless. 2013. Closing the Deficit: How Much Can Later Retirement Help? Washington, DC: The Brookings Institution Press.

Andreev, K., and J. Vaupel. 2005. "Patterns of Mortality Improvement Over Age and Time in Developed Counties: Estimation, Presentation, and Implications for Mortality Forecasting.” Paper Presented at PAA Annual Meetings. Philadelphia, PA.

Bell, Felicitie C. and Michael L. Miller. 2005. "Life Tables for the United States Social Security Area 1900-2100.” Actuarial Study No. 120. Washington, DC: U.S. Social Security Administration.

Bound, John, Arline Geronimus, Javier Rodriguez, and Timothy Waidmann. 2014. "The Implications of Differential Trends in Mortality for Social Security Policy.” Paper Presented at $16^{\text {th }}$ Annual Meeting of the Retirement Research Consortium. Washington, DC.

Brown, Jeffrey, Jeffrey B. Liebman, and Joshua Pollet. 2002. "Appendix: Estimating Life Tables That Reflect Socioeconomic Differences in Mortality.” In The Distributional Aspects of Social Security and Social Security Reform, edited by Martin Feldstein and Jeffrey B. Liebman. Chicago, IL: University of Chicago Press.

Cutler, David. 2009. “Estimating Work Capacity Among Near Elderly and Elderly Men.” Working Paper 09-18. Cambridge, MA: National Bureau of Economic Research.

Cutler, David M., Fabian Lange, Ellen Meara, Seth Richards-Shubik, and Christopher J. Ruhm. 2011. "Rising Educational Gradients in Mortality: The Role of Behavioral Risk Factors." Journal of Health Economics 30(6): 1174-1187.

Gavrilov, Leonid A., and Natalia S. Gavriloca. 2011. "Mortality Measurement at Advanced Ages: A Study of the Social Security Administration Death Master File.” North American Actuarial Journal 15(3): 432-447.

Gompertz, Benjamin. 1825. "On the Nature of the Function Expressive of the Law of Human Mortality and on a New Mode of Determining the Value of Life Contingencies." Philosophical Transactions of the Royal Society of London 115: 513-585.

Haverstick, Kelly, Margarita Sapozhnikov, Robert K. Triest, and Natalia A. Zhivan. 2007. “A New Approach to Raising Social Security’s Earliest Eligibility Age.” Working Paper 2007-19. Chestnut Hill, MA: Center for Retirement Research at Boston College.

Johnson, Nan E. 2000. “The Racial Crossover in Comorbidity, Disability, and Mortality.” Demography 37(3): 267-283. 
Kitagawa, Evelyn Mae and Philip Morris Hauser. 1973. Differential Mortality in the United States: A Study in Socioeconomic Epidemiology. Cambridge, MA: Harvard University Press.

Lee, Ronald D. and Lawrence R. Carter. 1992. "Modeling and Forecasting U.S. Mortality.” Journal of American Statistical Association 87(419): 659-671.

Leonesio, Michael V, Denton R. Vaughn, and Bernard Wixon. 2003. "Increasing the Early Retirement Age under Social Security: Health, Work, and Financial Resources.” Health and Income Security for an Aging Workforce, No. 7. Washington, DC: National Academy of Social Insurance.

Lu, Joseph and Wun Wong. 2011. "Mortality Improvement in the USA: Analysis Projections and Extreme Scenarios.” Paper Presented at Living to 100 Symposium. Orlando, FL.

Lynch, Scott M., J. Scott Brown, and Katherine G. Harmsen. "Black-White Differences in Mortality Compression and Deceleration and the Mortality Crossover Reconsidered." Research on Aging 25(3): 456-483.

Monk, Courtney, John A. Turner, and Natalia A. Zhivan. 2010. “Adjusting Social Security for Increasing Life Expectancy: Effects on Progressivity.” Working Paper 2010-9. Chestnut Hill, MA: Center for Retirement Research at Boston College.

Munnell, Alicia H. 2015. “The Average Retirement Age - An Update.” Issue in Brief 15-4. Chestnut Hill, MA: Center for Retirement Research at Boston College.

Munnell, Alicia and Jerilyn Libby. 2007. "Will People be Healthy Enough to Work Longer?” Issue in Brief 7-3. Chestnut Hill, MA: Center for Retirement Research at Boston College.

Olshansky, S. Jay, Toni Antonucci, Lisa Berkman, Robert H. Binstock, Axel Boersch-Supan, John T. Cacioppo, Bruce A. Carnes, Laura L. Carstensen, Lina P. Fried, Dana P. Goldman, James Jackson, Martin Kohli, John Rother, Yuhui Zheng, and John Rowe. 2012. "Differences in Life Expectancy Due to Race and Educational Differences Are Widening, and Many May Not Catch Up.” Health Affairs 31(8): 1803-1813.

Panis, Constantijn, Michael Hurd, David Loughran, Julie Zissimopoulos, Steven Haider, and Patricia St. Clair. 2002. "The Effects of Changing Social Security Administration's Early Entitlement Age and the Normal Retirement Age.” DRU-2903-SSA. Santa Monica, CA: RAND.

Pappas, Gregory, Susan Queen, Wilbur Hadden, and Gail Fisher. 1993. “The Increasing Disparity in Mortality between Socioeconomic Groups in the United States, 1960 and 1986.” New England Journal of Medicine 329(2): 103-109. 
Rogot, Eugene, Paul D. Sorlie, and Norman J. Johnson. 1992. "Life Expectancy by Employment Status, Income, and Education in the National Longitudinal Mortality Study.” Public Health Reports 107(4): 457-461.

Turner, John A. 2007. "Work at Older Ages; Is Raising the Early Retirement Age an Option for Social Security Reform?” Working Paper 2007-13. Chestnut Hill, MA: Center for Retirement Research at Boston College.

U.S. Social Security Administration. 2015. The Long-Range Demographic Assumptions for the 2015 Trustees Report, Table 2.2. Washington, DC.

Waldron, Hilary. 2007. "Trends in Mortality Differentials and Life Expectancy for Male Social Security-Covered Workers, by Socioeconomic Status.” Social Security Bulletin 67(3): 128.

. 2013. "Mortality Differentials by Lifetime Earnings Decile: Implications for Evaluations of Proposed Social Security Law Changes.” Social Security Bulletin 73(1): 1-37.

Wang, Haidong, Austin E. Schumacher, Carly E. Levitz, Ali H. Mokdad, and Christopher J.L. Murray. 2013. "Left Behind: Widening Disparities for Males and Females in US County Life Expectancy, 1985-2010.” Population Health Metrics 11(8): 1-15.

Weller, Christian E. 2005. "Raising the Retirement Age for Social Security: Implications for Low Wage, Minority, and Female Workers.” CAP Economic Policy Report. Washington, DC: Center for American Progress.

Yao, Li and Stephanie A. Robert. 2011. "Examining the Racial Crossover in Mortality Between African American and White Older Adults: A Multilevel Survival Analysis of Race, Individual Socioeconomic Status, and Neighborhood Socioeconomic Context.” Journal of Aging Research June: 1-8. 
Table 1. Sample Sizes by Birth Year

\begin{tabular}{lr}
\hline & Number of individuals \\
\hline Total sample & $3,731,062$ \\
Drop 1980 Census cohort & $3,606,717$ \\
Drop non-relatives to HH head & $3,370,151$ \\
Drop if born after 1960 or younger than 25 & $1,601,534$ \\
Drop if missing variables needed for education reassignment & $1,537,686$ \\
Final sample, weighted & $1,536,093$ \\
& \\
Final sample by birth year, weighted & \\
$1877-1890$ & 1,754 \\
$1891-1895$ & 5,579 \\
$1896-1900$ & 13,756 \\
$1901-1905$ & 26,717 \\
$1906-1910$ & 43,388 \\
$1911-1915$ & 63,966 \\
$1916-1920$ & 84,119 \\
$1921-1925$ & 112,443 \\
$1926-1930$ & 126,344 \\
$1931-1935$ & 127,556 \\
$1936-1940$ & 138,164 \\
$1941-1945$ & 168,688 \\
$1946-1950$ & 218,063 \\
$1951-1955$ & 245,072 \\
$1956-1959$ & 160,484 \\
\hline
\end{tabular}

Source: Tabulations from restricted National Longitudinal Mortality Study (NLMS) data provided by the U.S. Census Bureau, 1979-2011. 
Table 2. Pooled Regression Results

\begin{tabular}{lccl}
\hline & Age & Years since 1979 & Constant \\
\hline Males & 0.085 & -0.020 & -0.106 \\
& $(0.001)$ & $(0.001)$ & $(0.018)$ \\
Females & 0.091 & -0.007 & -0.869 \\
& $(0.001)$ & $(0.001)$ & $(0.020)$ \\
Overall & 0.085 & -0.011 & -0.505 \\
& $(0.001)$ & $(0.001)$ & $(0.019)$ \\
\hline
\end{tabular}

Source: Authors' calculations using tabulations from restricted NLMS data provided by the U.S. Census Bureau, 1979-2011. 
Table 3. Regression Results by Educational Quartile

\begin{tabular}{lrrr}
\hline & Age & Years since 1979 & Constant \\
\hline Males & & & \\
Lowest quartile & 0.076 & -0.015 & 0.224 \\
Second quartile & $(0.001)$ & $(0.001)$ & $(0.017)$ \\
& 0.085 & -0.020 & 0.003 \\
Third quartile & $(0.001)$ & $(0.001)$ & $(0.020)$ \\
& 0.087 & -0.022 & -0.062 \\
Highest quartile & $(0.001)$ & $(0.001)$ & $(0.019)$ \\
Females & 0.100 & -0.025 & -0.523 \\
Lowest quartile & $(0.001)$ & $(0.001)$ & $(0.019)$ \\
Second quartile & & & \\
& 0.080 & -0.005 & -0.474 \\
Third quartile & $(0.001)$ & $(0.001)$ & $(0.020)$ \\
Highest quartile & 0.091 & -0.010 & -0.777 \\
& $(0.001)$ & $(0.001)$ & $(0.022)$ \\
& 0.096 & -0.009 & -0.958 \\
& $(0.001)$ & $(0.001)$ & $(0.021)$ \\
& 0.103 & -0.012 & -1.218 \\
& $(0.001)$ & $(0.001)$ & $(0.023)$ \\
\hline
\end{tabular}

Note: Numbers in parentheses are standard errors. All coefficients are significantly different from zero at the 1percent level. The age variable is the difference between the respondent's current age and 52. Each observation is an age-year cell.

Source: Authors' calculations using tabulations from restricted NLMS data provided by the U.S. Census Bureau, 1979-2011. 
Table 4. Differences in Regression Coefficients by Educational Quartile

\begin{tabular}{lccc}
\hline & Age & Years since 1979 & Constant \\
\hline Males & & & \\
Difference second and lowest quartile & $0.009^{* * *}$ & $-0.005^{* * *}$ & $-0.221^{* * *}$ \\
& $(0.001)$ & $(0.001)$ & $(0.026)$ \\
Difference third and second quartile & $0.002^{* * *}$ & $-0.002^{*}$ & $-0.065^{* *}$ \\
& $(0.001)$ & $(0.001)$ & $(0.026)$ \\
Difference highest and third quartile & $0.013^{* * *}$ & $-0.003^{* * *}$ & $-0.461^{* * *}$ \\
Females & $(0.001)$ & $(0.001)$ & $(0.027)$ \\
Difference second and lowest quartile & $0.010^{* * *}$ & $-0.005^{* * *}$ & $-0.303^{* * *}$ \\
& $(0.001)$ & $(0.001)$ & $(0.029)$ \\
Difference third and second quartile & $0.005^{* * *}$ & 0.001 & $-0.181^{* * *}$ \\
& $(0.001)$ & $(0.001)$ & $(0.031)$ \\
Difference highest and third quartile & $0.007^{* * *}$ & $-0.004 * * *$ & $-0.260^{* * *}$ \\
& $(0.001)$ & $(0.001)$ & $(0.032)$ \\
\hline
\end{tabular}

Note: *** Indicates a statistical difference in the coefficients between the two educational groups at the 1-percent level of significance. ${ }^{* *}$ Indicates a statistical difference in the coefficients between the two educational groups at the 5-percent level of significance. Numbers in parentheses are standard errors on the difference between the two coefficients. The age variable is the difference between the respondent's current age and 52. Each observation is an age-year cell.

Source: Authors' calculations using tabulations from restricted NLMS data provided by the U.S. Census Bureau, 1979-2011. 


\section{9 cohort 2011 cohort $\quad$ Difference}

I. Conditional on Surviving to Age 65

Males

Lowest quartile

Second quartile

Third quartile

Highest quartile

Females

Lowest quartile

Second quartile

Third quartile

Highest quartile

\section{Conditional on Surviving to Age 22}

Males

Lowest quartile

Second quartile

Third quartile

Highest quartile

Females

Lowest quartile

Second quartile

Third quartile

Highest quartile

$\begin{array}{lll}77.5 & 81.5 & 4.0 \\ 77.7 & 82.8 & 5.1 \\ 77.8 & 83.3 & 5.5 \\ 78.9 & 85.0 & 6.1\end{array}$

82.3

83.7

1.4

82.6

85.3

2.7

82.9

85.2

2.3

83.4

86.6

3.2 5.1 5.5 6.1

4 
Table 6. Ratio of the Expected Number of Retirement Years to the Expected Number of Working Years by Full Retirement Age (FRA)

1979 mortality, 2011 mortality, 2011 mortality, FRA 65 FRA 65 FRA 66

\section{Conditional on Surviving to Age 65}

Males

Lowest quartile

0.29

0.38

0.36

Second quartile

0.30

0.41

0.39

Third quartile

0.30

0.43

0.40

Highest quartile

0.32

0.46

0.44

Unweighted average

0.30

0.42

0.40

Females

Lowest quartile

0.40

0.44

0.41

Second quartile

0.41

0.47

0.44

Third quartile

0.42

0.47

0.44

Highest quartile

0.43

0.50

0.47

Unweighted average

0.41

0.47

0.44

\section{Conditional on Surviving to Age 22}

Males

Lowest quartile

0.23

0.33

0.31

Second quartile

0.24

0.38

0.35

Third quartile

0.25

0.40

0.37

Highest quartile

0.29

0.45

0.42

Unweighted average

0.25

0.39

0.36

Females

Lowest quartile

0.36

0.40

0.37

Second quartile

0.38

0.45

0.42

Third quartile

0.39

0.45

0.42

Highest quartile

0.41

0.49

0.46

Unweighted average

0.39

0.45

0.42

Note: All workers are assumed to begin working at age 22, regardless of educational quartile.

Source: Authors' calculations using tabulations from restricted NLMS data provided by the U.S. Census Bureau, 1979-2011. 
Table 7. Retirement Age of the 2011 Cohort Adjusted to Produce Retirement to Working Years Ratio of the 1979 Cohort

\section{9 ratios by SES Average 1979 ratios}

\section{Conditional on Surviving to Age 65}

Males

Lowest quartile

Second quartile

Third quartile

Highest quartile

Females

Lowest quartile

Second quartile

Third quartile

Highest quartile
68.1

69.0

69.3

69.6

66.0

66.9

66.6

67.2

69.7

70.7

71.0

70.8

66.3

67.4

67.0

67.6
67.7

68.7

69.1

70.4

65.6

66.8

66.7

67.6

\section{Conditional on Surviving to Age 22}

Lowest quartile

Second quartile

Third quartile

Highest quartile

Females

Lowest quartile

Second quartile

Third quartile

Highest quartile

Note: All workers are assumed to begin working at age 22, regardless of educational quartile.

Source: Authors' calculations using tabulations from restricted NLMS data provided by the U.S. Census Bureau, 1979-2011. 
Figure 1a. Comparison of NLMS and SSA Mortality Rates (per 100), Males

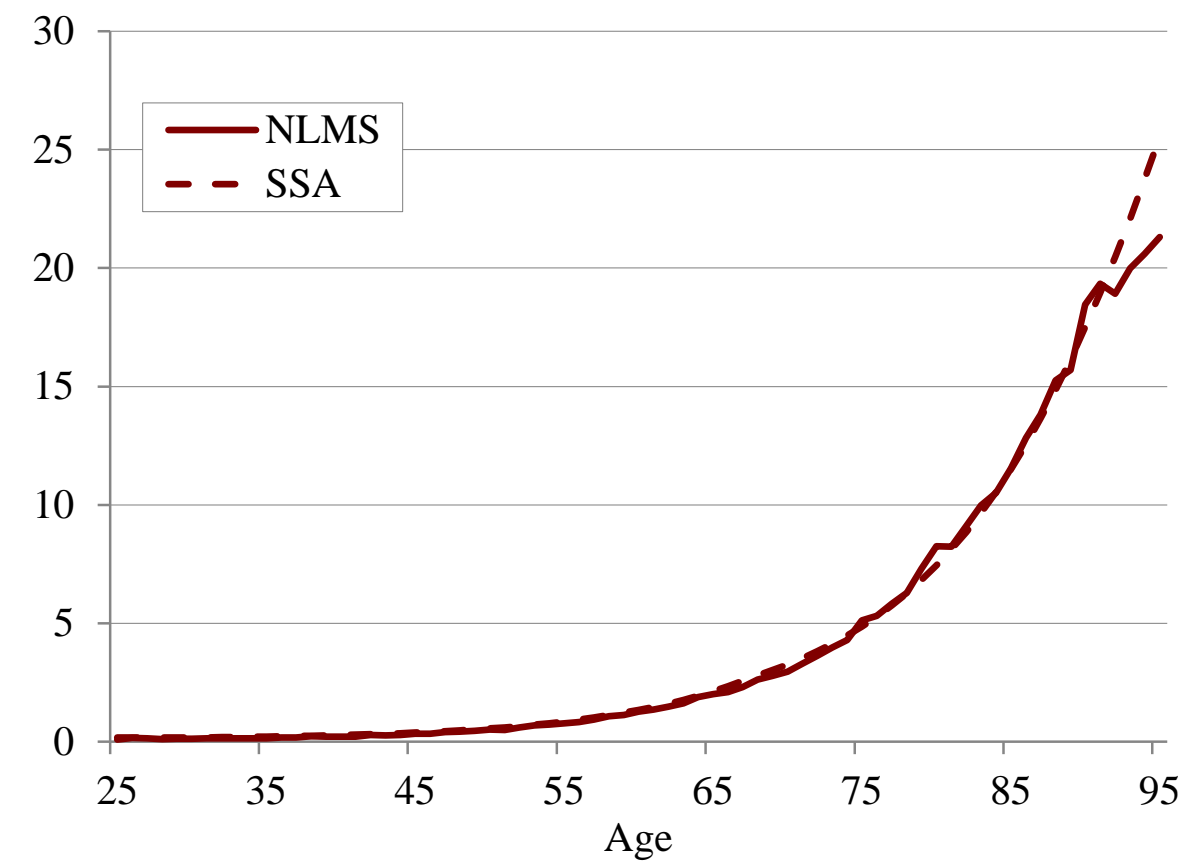

Source: Authors' calculations using tabulations from restricted NLMS data provided by the U.S. Census Bureau, 1979-2011.

Figure 1b. Comparison of NLMS and SSA Mortality Rates (per 100), Females

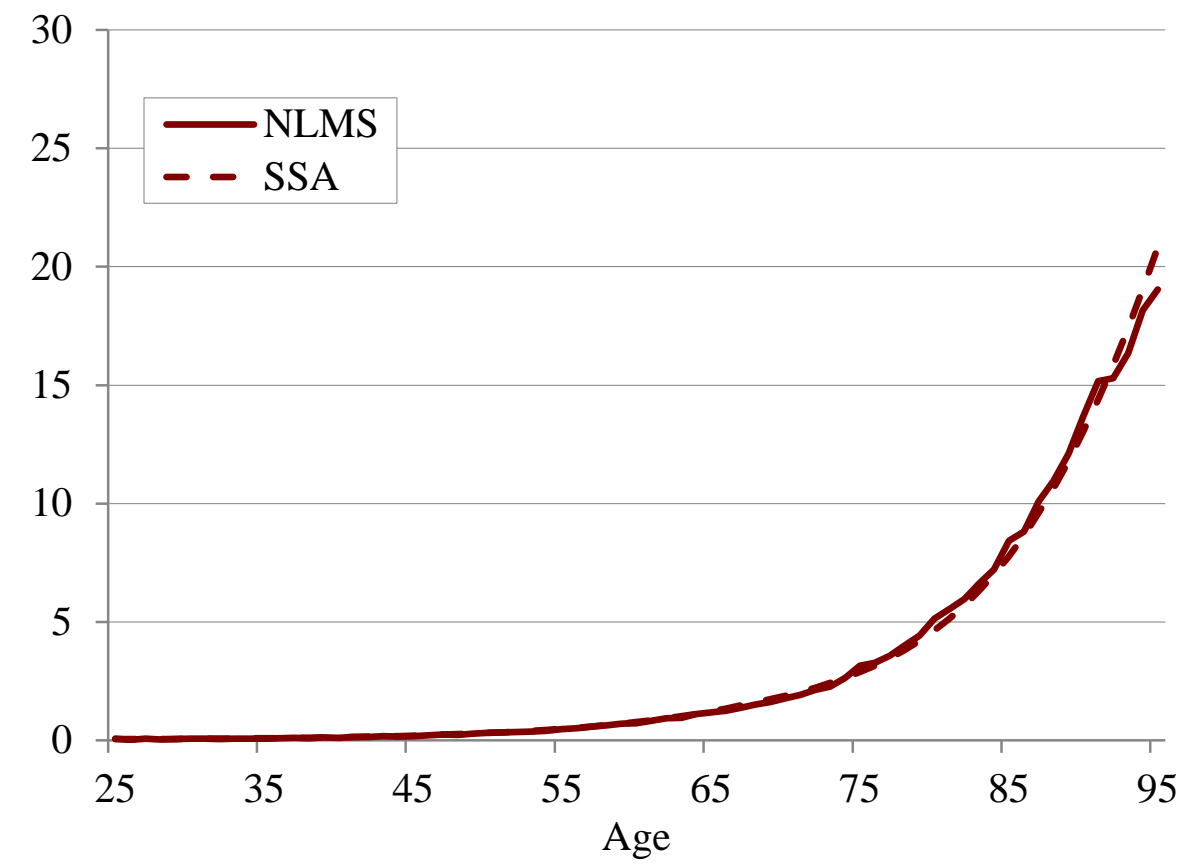

Source: Authors' calculations using tabulations from restricted NLMS data provided by the U.S. Census Bureau, 1979-2011. 
Figure 2a. Predicted Cumulative Survivor Probabilities for Males, 1914 Birth Cohort (65 in 1979) and 1946 Birth Cohort (65 in 2011), Lowest and Highest Educational Quartile

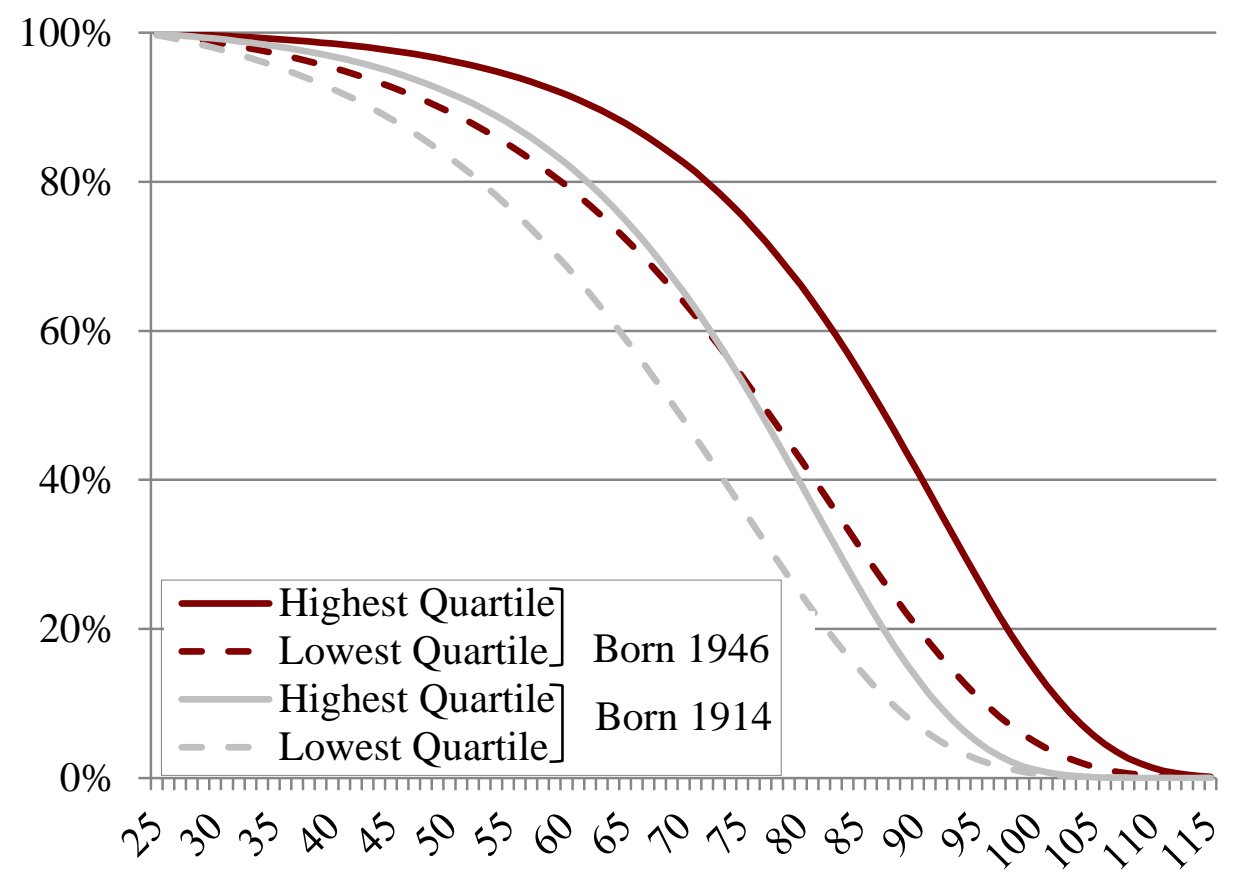

Note: Uses a "cohort” based calculation. For example, people turning 65 in 2011 are assumed to have 2010 mortality at age 64, 2012 mortality at 66 and so on.

Source: Authors' calculations using tabulations from restricted NLMS data provided by the U.S. Census Bureau, 1979-2011. 
Figure 2b. Predicted Cumulative Survivor Probabilities for Females, 1914 Birth Cohort (65 in 1979) and 1946 Birth Cohort (65 in 2011), Lowest and Highest Educational Quartile

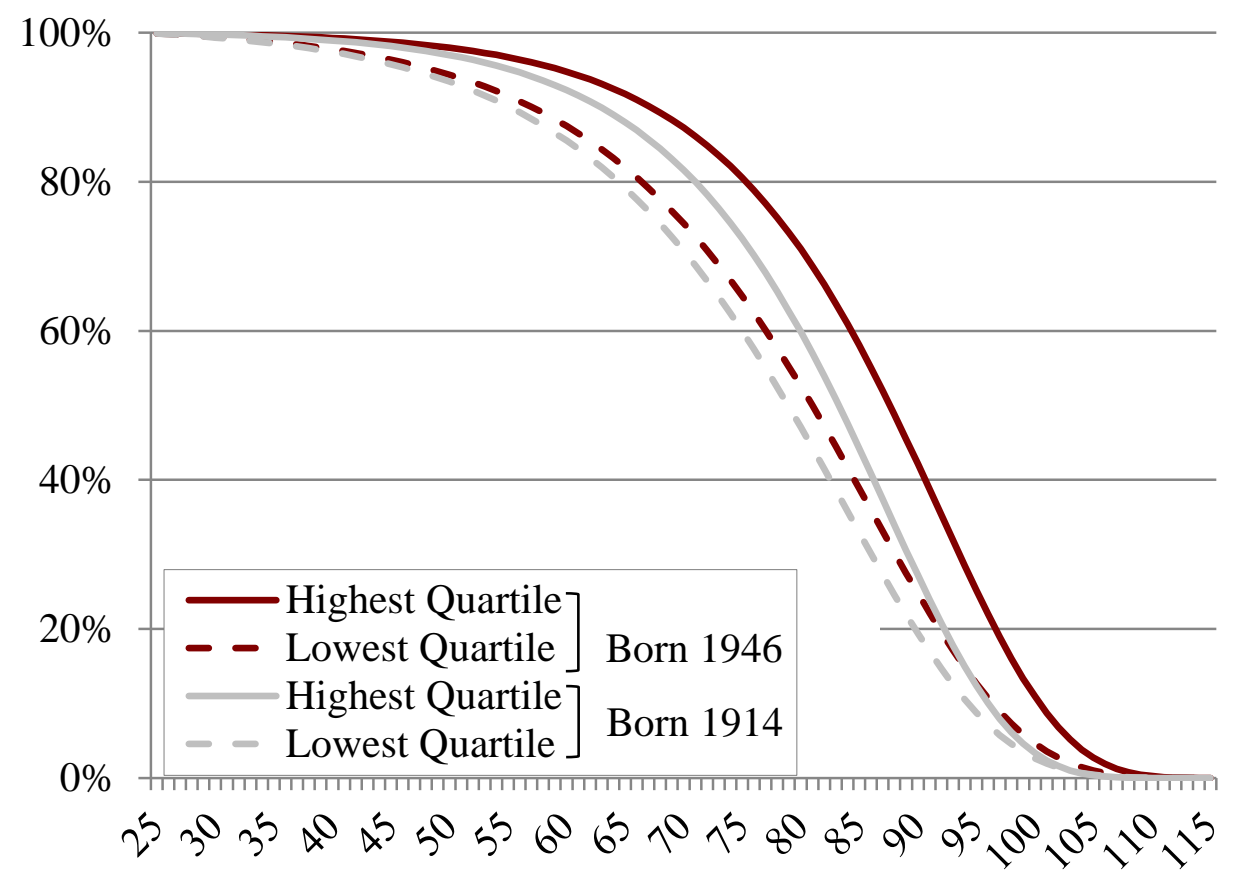

Note: Uses a "cohort" based calculation. For example, people turning 65 in 2011 are assumed to have 2010 mortality at age 64, 2012 mortality at 66 and so on.

Source: Authors' calculation using tabulations from restricted NLMS data provided by the U.S. Census Bureau, 1979-2011. 


\section{RECENT WORKING PAPERS FROM THE CENTER FOR RETIREMENT RESEARCH AT BOSTON COLLEGE}

How Does Occupational Access for Older Workers Differ by Education?

Matthew S. Rutledge, Steven A. Sass, and Jorge D. Ramos-Mercado, August 2015

How Much Longer Do People Need to Work?

Alicia H. Munnell, Anthony Webb, and Anqi Chen, August 2015

The Challenge of Pension Reform in Georgia: Non-Contributory Pensions and Elderly Poverty

Tamila Nutsubidze and Khatuna Nutsubidze, July 2015

The Transition from Defined Benefit to Defined Contribution Pensions: Does It Influence Elderly Poverty?

Natalia S. Orlova, Matthew S. Rutledge, and April Yanyuan Wu, July 2015

Will the Average Retirement Age Continue to Increase?

Matthew S. Rutledge, Christopher M. Gillis, and Anthony Webb, July 2015

The Role of Occupations in Differentiating Health Trajectories in Later Life

Michal Engelman and Heide Jackson, University of Wisconsin-Madison, July 2015

The Relationship Between Automatic Enrollment and DC Plan Contributions: Evidence from a National Survey of Older Workers

Barbara A. Butrica and Nadia S. Karamcheva, July 2015

Evidence of Increasing Differential Mortality: A Comparison of the HRS and SIPP Barry P. Bosworth and Kan Zhang, July 2015

Slowed or Sidelined? The Effect of "Normal” Cognitive Decline on Job Performance Among the Elderly

Anek Belbase, Mashfiqur R. Khan, Alicia H. Munnell, and Anthony Webb, June 2015

Does Social Security Continue to Favor Couples?

Nadia S. Karamcheva, April Yanyuan Wu, and Alicia H. Munnell, June 2015

Sources of Increasing Differential Mortality Among the Aged by Socioeconomic Status Barry P. Bosworth, Gary Burtless, and Kan Zhang, June 2015

Do Retired Americans Annuitize Too Little? Trends in the Share of Annuitized Income Barry P. Bosworth, Gary Burtless, and Mattan Alalouf, June 2015

All working papers are available on the Center for Retirement Research website (http://crr.bc.edu) and can be requested by e-mail (crr@bc.edu) or phone (617-552-1762). 